\title{
Comparative Efficacy of Bio-Agents and Botanicals on the Management of Diamondback Moth (Plutella xylostella Linn.) on Cabbage under Allahabad Agroclimatic Conditions
}

\author{
Huirem Diana Devi and Anoorag R. Tayde* \\ Department of Entomology, Naini Agricultural Institute, Sam Higginbottom University of \\ Agriculture, Technology and Sciences, Allahabad, India \\ *Corresponding author
}

\section{A B S T R A C T}

Keywords

Bacillus

thuringiensis,

Beauveria

bassiana,

Bio-agents,

Botanicals,

Plutella xylostella.

Article Info

Accepted:

14 June 2017

Available Online:

10 July 2017
In order to determine the comparative efficacy of some bio-agent (Bacillus thuringiensis and Beauveria bassiana) and botanicals (neem oil, NSKE, Neem leaf, tobacco, dhatura and Lantana camera) along with an untreated control against Plutella xylostella. Field trial was conducted during rabi season 20162017. Each insecticide was sprayed twice at 15 days interval. The larval count per plant was taken day before and 3, 7 and 14 days after each spray. All the insecticides tested significantly reduced the pest population compared to control. The highest percent reduction of diamondback moth larvae against control was observed in Bacillus thuringiensis (61.22\%). The mean crop yield ranged between $211 \mathrm{q} / \mathrm{ha}$ to $371 \mathrm{q} / \mathrm{ha}$ in the insecticidal treatment, the highest being Bacillus thuringiensis $(371 \mathrm{q} / \mathrm{ha}$ ) followed by Neem oil (331 q/ha). The cost benefit ratio varied from 1:3.1 to 1:6.9 in different insecticidal treatments, the highest in NSKE (1:6.9) followed by Neem oil (1:6.8).

\section{Introduction}

Cabbage is one of the most popular cole vegetables grown in India. It is commonly used fresh as boiled vegetables, cooked in curries and process, salad, etc. It is known to posses medicinal properties and its enlarged terminal buds is a rich source of $\mathrm{Ca}, \mathrm{P}, \mathrm{Na}, \mathrm{K}$, $\mathrm{S}$, Vitamin A, Vitamin $\mathrm{C}$ and dietary fibre. India is the second largest producer of cabbage after China. India is producing about 8534.5 million tonnes in an area of 372.24 ha with a productivity of $22.9 \mathrm{MT} / \mathrm{ha}$. In Uttar Pradesh cabbage is grown in an area of about 0.72 million ha producing 5.7 million tonnes.
The brassica crop has a multiple insect pest complex. The important insect pest species are Diamondback moth (Plutella xylostella L), Cabbage caterpillar (Pieris brassicae Linnaeus), Cabbage semi-looper (Thysanoplusia orichalcea Fabricius) and (Autographa nigrisigna Walker), Tobacco caterpillar (Spodoptera litura Fabricius), Cabbage leaf webber (Crocodolomia binotalis Zeller), Cabbage borer (Hellula undalis Fabricius) and Cabbage aphid (Brevicoryne brassicae W). Among the insect pests, diamondback moth, Plutella xylostella L. 
(Plutellidae: Lepidoptera) is the most destructive pest (Mahla et al., 2005). In India, Krishnamoorthy (2004) reported a 52\% yield loss on cabbage due to diamondback moth. Diamondback moth has developed resistant to almost all the group of chemical pesticides. This has necessitated the used of ecofriendly insecticides to sustain the management of diamondback moth. The efficacy of neem products and microbial insecticides like Bacillus thuringiensis has been reported by several workers (Nethravathi and Hugar, 2010; Raut and Simon, 2010 and Meena et al., 2011). Due to their efficacy in controlling the target pests without adversely affecting their natural enemies, bio-agents and botanicals ensures effectiveness, safety and acceptability to mankind. Hence the present study was undertaken for assessment of the efficacy of bio-agents and botanicals for managing Diamondback moth on cabbage and to study cost benefit ratio.

\section{Materials and Methods}

The investigation was conducted at the Central Research Field, Sam Higginbottom University of Agriculture, Technology and Sciences, Allahabad, Uttar Pradesh during rabi season of 2016-2017. Experiment was laid out in randomized block design (RBD) with 9 treatments including untreated control and replicated three times. One month old cabbage (cv Magic ball) seedlings were transplanted in the plot of $2 \mathrm{~m}^{2}$ area with $45 \mathrm{~cm} \times 30 \mathrm{~cm}$ spacing. All the recommended agronomic management practices were followed for raising the crop except the insecticidal spray. The field efficacy of selected bio-agents and botanicals viz., Bacillus thuringiensis (Dipel), Beauveria bassiana (Yash Beauveria) and Dhatura leaf extract, Tobacco leaf extract, Lantana camera leaf extract, Neem leaf extract, NSKE and Neem oil was compared with untreated control. Applications of the treatments were started as soon as the pest level crossed the ETL i.e., 2-3 larvae per plant the second spray was given after 15 days respectively. The population count of diamondback moth larvae was recorded by randomly selecting five plants from each plot. The population count of Diamondback moth larvae was recorded one day before every spray which served as pre-treatment observation and the subsequent counts were taken on $3^{\text {rd }}, 7^{\text {th }}$ and $14^{\text {th }}$ days after each spray (Post-treatment). Observation on the larval population were recorded during morning hours. In order to evaluate the effect of the treatments on the yield, the weight of cabbage heads were recorded. After attaining a desirable size the cabbage head were pluck. The weights of harvested heads in the plot of each treatment were sum-up to the total yield and computed on hectare basis by using hectare factor.

\section{Preparation of neem seed kernel and neem leaf extraction}

Neem kernel and neem leaf were collected from nearby locality of SHUATS, Allahabad. Kernels and neem leaf were crushed in to fine powder using grinder, and sieved using wire mesh. The extraction was made by mixing the powder with water in plastic container at the rate of $50 \mathrm{~g}$ powder per liter of water. After mixing the solution was stirrer carefully until all the powder mixed completely with the water. These solutions were left overnight. The following morning the extract were filter into the sprayer using plastic mesh sieve for field used.

\section{Preparation of dhatura leaf extraction}

Dhatura leaves were collected from nearby locality of SHUATS, Allahabad. Collected leaves were dried well and ground it to powder. $50 \mathrm{~g}$ dhatura powder was mixed with one liter of water. After mixing the solution was stirrer carefully until all the powder 
mixed completely with the water. The solution was left overnight. The following morning the extract were filter into the sprayer using plastic mesh sieve for field used.

\section{Preparation of tobacco leaf extraction}

Tobacco leaves were collected from local market, Allahabad. Collected tobacco leaves were dried well and ground it to powder. $125 \mathrm{~g}$ tobacco leaf powder was mixed with $2.0 \mathrm{~L}$ of water and boiled for 30 minutes. The mixture was cooled and filtered through muslin cloths and then $15 \mathrm{~g}$ detergent $8 \mathrm{~L}$ of water were added as a pickling agent. Finally this product was ready for spraying.

\section{Preparation of $L$. camera leaf extraction}

$1 \mathrm{~kg}$ of young fresh lantana leaf was collected and crushed into small pieces using knife, then the chopped leaf was ground using grinder with $250 \mathrm{ml}$ of water to make paste. The paste was strain through muslin cloth and kept for $24 \mathrm{~h}$. At the time of application the aqueous extract was diluted in $9.75 \mathrm{~L}$ water.

The data collected on percent reduction in population of Diamondback moth (Plutella xylostella) were subjected to statistical analysis for testing the level of significance. Similarly, the replication wise data of each treatment on yield of cabbage head were also subjected to analysis of variance.

\section{Results and Discussion}

The mean data on percent reduction of population of diamondback moth obtain at three, seven and fourteen days after first spray. Table 2 revealed that all the treatments significantly differed from the untreated control after first spray and reduction in the larval population of $P$. xylostella was observed in the all insecticidal treatments.
The maximum percentage of larval reduction was observed in Bacillus thuringiensis (58.14\%) followed by neem oil $(50.09 \%)$ whereas, control plot $(16.75 \%)$, showed least effectiveness. The overall mean of first spray shows that the treatment T2 Tobacco leaf extract $(28.23 \%)$ and $\mathrm{T} 7 \quad$ B. bassiana $(30.12 \%)$ are statistically non-significant with each other; treatment T4 neem leaf $(38.12 \%)$ and T5 NSKE (40.28\%) are also at par with each other. Similarly, after second spray the highest percentage reduction in larval population of $P$. xylostella was observed in Bacillus thuringiensis (64.29\%) followed by Neem oil (57.01\%) when compared to control (16.75\%). Among all the treatment, treatment T1 dhatura leaf extract $(29.25 \%)$ and T3 $L$. camera leaf extract $(27.66 \%)$ are also statistically non-significant with each other (Table 1).

The overall highest mean per cent reduction of $P$. xylostella in cabbage was observed in Bacillus thuringiensis (61.21\%) and Neem oil $(53.57 \%)$. All the treatments showed significant increase in yield over untreated control. Highest mean yield of cabbage was recorded in Bacillus thuringiensis (07.43 $\mathrm{kg} / \mathrm{plot})$ followed by Neem oil $(06.61 \mathrm{~kg} / \mathrm{plot})$ and NSKE (06.37 kg/plot), whereas the lowest yield was observed in untreated control $(03.28 \mathrm{~kg} / \mathrm{plot})$. Among the treatments T6 Neem oil $(06.61 \mathrm{~kg} / \mathrm{plot})$ and T5 Neem leaf extract $(06.36 \mathrm{~kg} / \mathrm{plot})$ are at par with each other, treatment T4 Neem leaf extract $(06.13 \mathrm{~kg} / \mathrm{plot})$ and $\mathrm{T} 7 \mathrm{~B}$. bassiana $(06.05$ $\mathrm{kg} / \mathrm{plot}$ ) are at par with each other, T7 B. bassiana $(06.05 \mathrm{~kg} / \mathrm{plot})$ and T2 Tobacco leaf extract $(05.35 \mathrm{~kg} / \mathrm{plot})$ are also at par with each other and again T2 Tobacco leaf extract $(05.35 \mathrm{~kg} / \mathrm{plot})$ and T1 Dhatura leaf extract $(04.49 \mathrm{~kg} / \mathrm{plot})$ were found statistically at par with each other. T1 Dhatura leaf extract $(04.49 \mathrm{~kg} / \mathrm{plot})$ and T3 L. camera (04.23 $\mathrm{kg} / \mathrm{plot}$ ) were also at par with each other. Thus, B. thuringiensis is highly effective 
against $P$. xylostella, which is the most important and destructive pest of cruciferous crop. The present findings are in conformity with the results of Vanlaldiki et al., (2013) who reported that $B$. thuringiensis gave the minimum larval population after $(3,7$ and 10 DAA) against DBM P. xylostella. Similarly the superior of $B$. thuringiensis formulation for the control of DBM population has also been consistently found by other researchers (Leibee and Sevage, 1992; Seal, 1995 and Asokan et al., 1996.). Sontakke et al., (2014) also reported that a product of $B$. thuringiensis (Lipel and Xen tari) was found to be most effective against was $P$. xylostella. Malathi and Sriramulu (2000) also mentioned about the effectiveness of $B t$ against lepidopterous pests. Although the yield of the plot treated with $B$. thuringiensis and neem oil were higher than NSKE, due to their higher cost of treatment they failed to show higher $\mathrm{B}$ : $\mathrm{C}$ ratio and higher cost benefit ratio was obtained from NSKE (1:6.9) treated plot. Saxena and Kidiavai (1970) also reported that highest (1:24.06) incremental cost benefit ratio (ICBR) was observed in NSKE because of its low cost, the treatment of neem oil ranked next to NSKE, but failed to show higher ICBR because of its higher cost and this result was supported by the finding of Karkar et al., (2014). Rahman et al., (2014) also observed higher MBCR (2.99) from NSKE treated fruits.

Table.1 Efficacy of bio-agents and botanicals on the management of

DBM larva and on yield in cabbage

\begin{tabular}{|c|c|c|c|c|}
\hline \multirow[t]{3}{*}{$\begin{array}{l}\text { Treatment } \\
\text { No. }\end{array}$} & \multirow[t]{3}{*}{$\begin{array}{l}\text { Treatment } \\
\text { (per L of water) }\end{array}$} & \multicolumn{2}{|c|}{$\begin{array}{l}\text { Percent reduction in larval population of } \\
\text { Diamondback moth }\end{array}$} & \multirow[t]{3}{*}{$\begin{array}{l}\text { Yield } \\
\text { (kg/plot) }\end{array}$} \\
\hline & & First Spray & Second Spray & \\
\hline & & Mean & Mean & \\
\hline $\mathrm{T} 1$ & $\begin{array}{l}\text { Dhatura leaf @ } \\
50 \mathrm{~g} / \mathrm{L}\end{array}$ & $24.56^{\mathrm{e}}$ & $29.25^{\mathrm{g}}$ & $4.49^{\mathrm{f}}$ \\
\hline $\mathrm{T} 2$ & $\begin{array}{l}\text { Tobacco leaf @ } \\
12.5 \mathrm{~g} / \mathrm{L}\end{array}$ & $28.23^{\mathrm{d}}$ & $38.71^{f}$ & $5.35^{\mathrm{e}}$ \\
\hline T3 & $\begin{array}{l}\text { Lantana camera } \\
\text { @ } 100 \mathrm{~g} / \mathrm{L}\end{array}$ & $21.95^{\mathrm{f}}$ & $27.66^{\mathrm{g}}$ & $4.23^{f}$ \\
\hline $\mathrm{T} 4$ & $\begin{array}{l}\text { Neem leaf @ } \\
50 \mathrm{~g} / \mathrm{L}\end{array}$ & $38.12^{\mathrm{c}}$ & $48.29^{\mathrm{d}}$ & $6.13^{\mathrm{cd}}$ \\
\hline $\mathrm{T} 5$ & NSKE @ 50g/L & $40.28^{\mathrm{c}}$ & $51.05^{\mathrm{c}}$ & $6.37^{\mathrm{bc}}$ \\
\hline T6 & $\begin{array}{l}\text { Neem oil@ } \\
3 \mathrm{ml} / \mathrm{L}\end{array}$ & $50.09^{b}$ & $57.01^{\mathrm{b}}$ & $6.61^{\mathrm{b}}$ \\
\hline $\mathrm{T} 7$ & $\begin{array}{l}\text { B. bassiana@ } \\
\text { 1g/L }\end{array}$ & $30.12^{\mathrm{d}}$ & $45.11^{\mathrm{e}}$ & $6.01^{\mathrm{d}}$ \\
\hline T8 & $\begin{array}{l}\text { Bacillus } \\
\text { thuringiensis@ } \\
4 \mathrm{~g} / \mathrm{L}\end{array}$ & $58.14^{\mathrm{a}}$ & $64.29^{\mathrm{a}}$ & $7.43^{\mathrm{a}}$ \\
\hline T0 & Control & $16.75^{\mathrm{g}}$ & $16.75^{\mathrm{g}}$ & $3.28^{\mathrm{g}}$ \\
\hline & S.Ed $(\underline{ \pm})$ & 1.20 & 0.92 & 0.13 \\
\hline & C.D. $(\mathrm{P}=0.05)$ & 2.549 & 1.946 & 0.28 \\
\hline
\end{tabular}


Table.2 Economics of cultivation

\begin{tabular}{|c|c|c|c|c|c|c|c|c|c|}
\hline $\begin{array}{l}\text { S } \\
\text { No. }\end{array}$ & Treatment & $\begin{array}{l}\text { Yield } \\
\text { (q/ha) }\end{array}$ & $\begin{array}{l}\text { Cost } \\
\text { of } \\
\text { yield } \\
\text { Rs/q }\end{array}$ & $\begin{array}{l}\text { Total } \\
\text { cost of } \\
\text { yield } \\
\text { (Rs) }\end{array}$ & $\begin{array}{l}\text { Common } \\
\text { cost }(\mathrm{Rs})\end{array}$ & $\begin{array}{l}\text { Treatment } \\
\text { cost (Rs) }\end{array}$ & $\begin{array}{l}\text { Total } \\
\text { cost } \\
\text { (Rs) }\end{array}$ & $\begin{array}{l}\text { Net } \\
\text { returns } \\
\text { (Rs) }\end{array}$ & $\begin{array}{l}\text { B:C } \\
\text { ratio }\end{array}$ \\
\hline T1 & Dhatura leaf & 224.50 & 700 & 157150 & 27513 & 600 & 28113 & 129037 & $1: 4.5$ \\
\hline $\mathrm{T} 2$ & Tobacco leaf & 267.50 & 700 & 187250 & 27513 & 4050 & 31563 & 155687 & $1: 4.9$ \\
\hline T3 & $\begin{array}{l}\text { Lantana } \\
\text { camera }\end{array}$ & 211.50 & 700 & 148050 & 27513 & 600 & 28113 & 119937 & $1: 4.2$ \\
\hline T4 & Neem leaf & 306.50 & 700 & 214550 & 27513 & 600 & 28113 & 186437 & $1: 6.6$ \\
\hline T5 & NSKE & 318.50 & 700 & 222950 & 27513 & 600 & 28113 & 194837 & $1: 6.9$ \\
\hline T6 & Neem oil & 331.00 & 700 & 231700 & 27513 & 2112 & 29625 & 202075 & $1: 6.8$ \\
\hline $\mathrm{T} 7$ & $\begin{array}{c}\text { Beauveria } \\
\text { bassiana }\end{array}$ & 300.80 & 700 & 210583 & 27513 & 780 & 28293 & 182290 & $1: 6.4$ \\
\hline T8 & B. thuringiensis & 371.50 & 700 & 260050 & 27513 & 9240 & 36753 & 223297 & $1: 6.07$ \\
\hline & Control & 164.00 & 700 & 114800 & 27513 & --------- & 27513 & 87287 & $1: 3.1$ \\
\hline
\end{tabular}

\section{Acknowledgement}

I would like to take this opportunity to express my profound gratitude and deep regard to Dr. Anoorag Tayde, Assistant professor, Department of Entomology. SHUATS, Allahabad for his exemplary guidance, valuable feedback and constant encouragement throughout the duration of the research. His valuable suggestions were of immense help throughout my research work. I would also like to show my gratitude to the Department of Plant Protection, SHUATS, Allahabad for providing Central Research Field to conduct my research work and helping me in accomplishing my project.

\section{References}

Asokan, M., Mohan, K.S. and Gopalakrishnan, C. 1996. Effect of commercial formulations of Bacillus thuringiensis Berliner on yield of cabbage. Insect Environ., 2(2): 58-59.

Gomez, K.A. and Gomez, A.A. 1984. Square root transformation in statistical procedures for Agricultural Research. JohnWiley and sons, New York. Pp. 304.

Karkar, D.B., Korat, D.M. and Dabhi, M.R. 2014. Evaluation of botanicals for their bio-efficacy against insect pests of brinjal. Karnataka J. Agric. Sci., 27(2): 145-147.

Krishnamoorthy, A. 2004. Biological control of diamondback moth Plutella xylostella (L.), an Indian scenario with reference to past and fu-ture strategies. In Proceedings of the International Symposium (Eds AA Kirk D Bordat), 21-24 October 2002, Montpellier, France, CIRAD, pp. 204-11.

Leibee, G.L. and Sevage, K.E. 1992. Evaluation of selected insecticides for 
control of diamondback moth and cabbage looper in cabbage in Central Florida with observation on insecticide resistance in the diamondback moth. Florida Entomologists, 75(4): 585-591.

Mahla, R.S., Singh, S. and Chaudhary, P. 2005. Management of diamondback moth, Plutella xylostella (L.) larvae by entomopathogenic fungus, Metarhizium anisopliae. Indian J. Entomol., 67: 342344.

Malathi, S. and Sriramulu, M. 2000. Laboratory efficacy of biotic insecticides against lepidopterous pests feed on cabbage leaves. Shashpa, 7(1): 63-66.

Meena, R.K., Ram, J. and Lal, O.P. 2011. Bio-efficacy of some commercially available Neem formulations on Diamondback moth, Plutella xylostella (L.) on cabbage. J Progressive Agric., 2(2): 55-56.

Nethravathi, C. and Hugar, P.S. 2010. Bioefficacy of Chikkamagalur native Bacillus thuringiensis isolates against lepidopteran insects. J. Biol. Cont., 24(3): 282-284

Rahman, A.K.M.Z., Haque, Alam, S.N., Mahmudunnabi, M. and Dutta, N.K. 2014. Efficacy of Botanicals against
Helicoverpa armigera (Hubner) in Tomato. The Agriculturists, 12(1): 131139.

Raut, A. and Simon, S. 2010. Comparative efficacy of some bio-pesticides and insecticide against diamondback moth, Plutella xylostella (L.) on cabbage in Allahabad, U.P. Trends Biosci., 3(2): 174-175.

Saxena, R.C. and Kidiavai, E.L. 1997. Neem seed extract spray applications as lowcost inputs for management of flower thrips in cowpea crop. Phytoparasitica, 25(2): 99-110.

Seal, D.R. 1995. Management of diamondback moth, Plutella xylostella using biological insecticides. Proceedings of the Florida State Horticultural Soc., Pp. 197-201.

Sontakke, P.P., Behere, G.T., Firake, D.M. and Thubru, D.P. 2014. Evaluation of toxicity and cotoxicity of biopesticides against Diamondback moth, Plutella xylostella (L). J. Biopest, 7(1): 90-97.

Vanlaldiki, H., Premjit, M., Robert, L. 2013. Efficacy of eco-friendly insecticides on the management of diamondback moth (Plutella xylostella Linn.) on cabbage. Bioscan, 8(4): 1225-1230.

\section{How to cite this article:}

Huirem Diana Devi and Anoorag R. Tayde. 2017. Comparative Efficacy of Bio-Agents and Botanicals on the Management of Diamondback Moth (Plutella xylostella Linn.) on Cabbage under Allahabad Agroclimatic Conditions. Int.J.Curr.Microbiol.App.Sci. 6(7): 711-716. doi: https://doi.org/10.20546/ijcmas.2017.607.088 